\title{
ADSORPTION OF CONGO RED USING KAOLINITE-CELLULOSE ADSORBENT
}

\author{
Santa Oktavia Ginting ${ }^{1 *}$, Risfidian Mohadi ${ }^{1}$ \\ ${ }^{1}$ Department of Chemistry, Faculty of Mathematic and Natural Sciences Sriwijaya University \\ *Corresponding Author Email: gintingsanta86@gmail.com
}

\begin{abstract}
Kaolinite was impregnated with cellulose extracted from rubber wood fibers has been done. The product of impregnated kaolinite-cellulose was characterized using FT-IR spectrophotometer. Furthermore, the impregnation results are used as an adsorbent of Congo red. Adsorption of Congo red was also studied the kinetic and thermodynamic parameters. The results of characterization using FT-IR spectrophotometer shows the process of impregnation was successfully conducted. It was indicated that the presence wavenumber at $910.4-918.12 \mathrm{~cm}^{-1}$ and $1033.85 \mathrm{~cm}^{-1}$ become $1026.13 \mathrm{~cm}^{-1}$ and the existence of vibration at wavenumber $2931.8 \mathrm{~cm}^{-1}$. The $\mathrm{pH}$ of adsorption was adjusted to 4 before the adsorption process. The adsorption process of cellulose impregnated kaolinite shows the rate of adsorption (k) of $0.002 \mathrm{~min}^{-1}$, the adsorption reviews largest capacity (b) at $50{ }^{\circ} \mathrm{C}$ was $500 \mathrm{~mol} / \mathrm{g}$. The greatest adsorption energy (E) at $40{ }^{\circ} \mathrm{C}$ is 11:09 $\mathrm{kJ} / \mathrm{mol}$. The enthalpy value $(\Delta \mathrm{H})$ and entropy $(\Delta \mathrm{S})$ decreased with increasing Congo red dye concentration.
\end{abstract}

Keywords: kaolinite, cellulose, impregnation, Congo red

\section{INTRODUCTION}

Clay is a material that consists of mineral rich in alumina, silica, and water. Clay mineral is layered silicate and commonly found in nature. One example of a layered material or clay is widely known that kaolinite (Deng, et.al, 2017). The chemical formula of pure kaolinite is aluminum silicate hydrate $\left(\mathrm{Al}_{2} \mathrm{O}_{3} \cdot 2 \mathrm{SiO}_{2} \cdot 2 \mathrm{H}_{2} \mathrm{O}\right)$. The minerals include kaolinite group is kaolinite, nacrite, and halloysite, with its main mineral kaolinite (Kovács and Makó, 2016).

In recent years, kaolinite has become the materials used for several of industrial processes due to its excellent performance like good bonding ability, a good electrical insulator, and thermal stability. However, it is rarely used as an adsorbent for the low cations exchange capacity and a small specific surface area (Koteja and Matusik, 2015). Crystal structure of kaolinite is classified to the type phyllosilicates 1: 1 . This crystal consists of sheets octahedral aluminum, $\mathrm{Al}^{3+}$ coordinated to the anion $\mathrm{OH}^{-}$stacked sheets of silica tetrahedral, $\mathrm{Si}^{4+}$ coordinated to the anion $\mathrm{O}^{2-}(\mathrm{Yu}$, et.al, 2016).

As an inorganic polymer, kaolinite minerals classified as inorganic ion exchangers who can naturally perform the exchange process with other ions from the outside with the influence of water (Chemeda, et.al, 2015). The clay structure is negatively charged and binding of cations to neutralize the charge. The negative charge is derived from the ratio between silica and alumina ( $\mathrm{Si} / \mathrm{Al}$ ) which is relatively small and the surface of the kaolinite that has oxygen and hydroxyl groups sticking out, causing the negatively charged (Pietzsch et.al, 2015).

One of effort to improve the absorption of kaolin as an adsorbent can be modified by impregnation method. The impregnation is a process in which an adsorbent material that coats so that the active group of the material is also capable of binding the compound to be absorbed (Aung et.al, 2015). Impregnation technique

\section{Article History}

Received : 4 October 2016

Received in revised form : 2 January 2017

Accepted : 5 January 2017

DOI: 10.26554/sti.2017.2.2.29-36

(C)2017 Published under the term of the CC BY NC SA license can be done with certain organic materials and the process is easy and simple. Organic materials that can be used to modify the clay are cellulose, cellulose used because its existence is abundant in nature. Judging from the structure of cellulose has a huge potential to be used as adsorbent, because the $-\mathrm{OH}$ group that is bound to interact with the adsorbate. The presence of the -OH group in cellulose cause the polar properties on the adsorbent. Thus stronger cellulose absorbs substances that are polar substances that are less polar (Han et.al, 2016).

Studies of impregnation method have been carried out by Unuabonah et.al (2007) that has impregnated tripolyphosphate to kaolinite for adsorption of lead and cadmium. Chong et.al (2009) also reported impregnation of kaolinite using titania compound as material for photocatalyst.

The dye used in the apparel industry, paper, plastic, rubber, food and cosmetics to produce a colored product. The dye usually has a complex molecular structure which makes it more stable aromatic so difficult to disentangle biodegradable. Congo red is a dye that has an azo group $(\mathrm{R}-\mathrm{N}=\mathrm{N}-\mathrm{R})$. As the waste dye, where the dye Congo red, especially in the aquatic environment can damage a variety of species of life because of the nature of dye Congo red, which has a fairly high level of toxicity. If the dye Congo red accumulates in the human body can cause several health problems in humans (Sasmal et.al, 2017). Treatment and removal of Congo red from aqueous solution has been conducted by many researchers such as Said and Palapa (2017), which has Mg/Al hydrotalcite as material for adsorption of Congo red.

Concern on the effects of the textile dye Congo red on the environment and living beings in it, there should be efforts to minimize waste of the substance before being discharged into the water system. It requires an adsorbent that is able to absorb the dye better. Kaolinite impregnated cellulose is expected to be used as an adsorbent with a higher adsorption capacity, especially for organic molecules.

\section{EXPERIMENTAL SECTION}

Materials and Equipments

The materials used in this study are rubber wood fibers, kaolinite $\left(\mathrm{Al}_{2} \mathrm{O}_{3} .2 \mathrm{SiO}_{2} .2 \mathrm{H}_{2} \mathrm{O}\right)$, substance color Congo red $\left(\mathrm{C}_{32} \mathrm{H}_{22} \mathrm{~N}\right.$ - 
${ }_{6} \mathrm{Na}_{2} \mathrm{O}_{6} \mathrm{~S}_{2)}$, thiourea $\left(\left(\mathrm{NH}_{2}\right)_{2} \mathrm{CS}\right)$ and sulfuric acid $\left(\mathrm{H}_{2} \mathrm{SO}_{4)}\right.$, sodium hydroxide $(\mathrm{NaOH})$, hydrochloric acid $(\mathrm{HCl})$, and distilled water $\left(\mathrm{H}_{2} \mathrm{O}\right)$. The tools used in this research that flask glassware, analytical balance, furnace, magnetic stirrer, thermometer, bath (hotplate), oven, horizontal shaker, filter paper, pipette volume, pipette, cuvette, spectrophotometers Shimadzu FT-IR-Prestige-21, and UV-Vis spectrophotometer Thermo Scientific Geneysis 20.

\section{Preparation Rubber Wood Fiber}

A $100 \mathrm{~g}$ of rubber wood fibers was washed using hydrochloric acid ( $\mathrm{HCl} 0.1 \mathrm{M}$ ) with a certain volume for 3 hours while shaked. Washing results then filtered, and the solids obtained were washed with water and followed by washing using $0.1 \mathrm{M} \mathrm{NaOH}$ with a certain volume for 3 hours while shaked. Results immersion then filtered, and the solids obtained were washed with water until the washing water has a neutral $\mathrm{pH}$. Then the solids are dried and the obtained results in the form of cellulose $1 \mathrm{x}$ washing characterized using FT-IR spectrophotometer. The characterization results compared to standard cellulose. The procedure is repeated from the beginning to get the cellulose $2 \mathrm{x}, 3 \mathrm{x}$, and $4 \mathrm{x}$ wash.

\section{Determination of Water Content}

The water content is determined by measuring the sample weight measurements before and after heating. A total of $1 \mathrm{~g}$ of rubber wood fibers incorporated into a petri dish of known weight. The wood fiber was heated in an oven at $110{ }^{\circ} \mathrm{C}$ for 5 hours, then allowed to stand and weighed. This procedure applies to launder $2 \mathrm{x}, 3 \mathrm{x}$, and $4 \mathrm{x}$ to obtain a constant weight.

\section{Determination of Ash Content}

The ash content is determined by incorporating $1 \mathrm{~g}$ of wood fiber (washed) in exchange porcelain that has been known weight. The wood fiber is heated into the furnace at a temperature of 400 ${ }^{\circ} \mathrm{C}$ for 2 hours to form ash, then allowed to stand and weighed. The procedure applies to launder $2 \mathrm{x}, 3 \mathrm{x}$, and $4 \mathrm{x}$ to obtain cash heavy.

\section{Preparation and Activation Kaolinite}

Preparation kaolinite is done by two types i.e. physical and chemical activation. For physical activation, a $100 \mathrm{~g}$ of kaolinite was heated using the furnace at a temperature of $400{ }^{\circ} \mathrm{C}$ for 2 hours and then allowed to stand at room temperature. The Kaolinite was named heated Kaolinite. The other kaolinite was processed by chemical/acidification process. Acidification is done by dissolving $20 \mathrm{~g}$ of kaolinite which has been heated at a temperature of $400{ }^{\circ} \mathrm{C}$ into $200 \mathrm{ml}$ of sulfuric acid $\left(\mathrm{H}_{2} \mathrm{SO}_{4}\right.$ the concentration of each $1 \%, 5 \%, 10 \%$, and $15 \%$ in the beaker glass separately and stirred for 3 hours. Once separated and filtered, then each dried solid at a temperature of $97^{\circ} \mathrm{C}$. Further kaolinite which has been prepared called acidified kaolinite. Natural kaolinite, heated kaolinite, and acidified kaolinite were characterized by using FT-IR spectrophotometer.

\section{Impregnation Kaolinite with Cellulose}

Impregnation process carried out as follow. Kaolinite solids-cellulose was prepared by adding $4 \mathrm{~g}$ of cellulose from wood fiber rubber into a mixture of $1.5 \mathrm{M} \mathrm{NaOH}$ solution and the solution of thiourea $1 \mathrm{M}$. The mixture was stored at $\quad 0{ }^{\circ} \mathrm{C}$ for 8 hours to obtain a solution (I). A $10 \mathrm{~g}$ of activated kaolinite mixed with $\mathrm{NaOH}$ $46 \%$ as much as $8 \mathrm{~mL}$ in ice water for 6 hours. A $52 \mathrm{~g}$ of ice was added to obtain a solution (II). The solution (I) and (II) are mixed and stirred for 30 minutes to obtain a solid, and then filtered. The solid is filtered drip with sulfuric acid $\left(\mathrm{H}_{2} \mathrm{SO}_{4}\right) 5 \%$ solids obtained are then dried and the impregnation result kaolinite-cellulose. Results of kaolinite-cellulose impregnation characterized using FT-IR spectrophotometer.

Applications of Cellulose Fibers Rubber Wood (Control), Activated Kaolinite and Kaolinite Impregnated Cellulose as Dye Adsorbent Congo Red

\section{Preparation of standard solution of Congo red}

Preparation of standard solution of dye Congo red made by diluting the mother liquor dye Congo red $1000 \mathrm{mg} / \mathrm{L}$ is used as a concentration of $10,20,30,40 \mathrm{mg} / \mathrm{L}$ gradually. Standard solution of dye Congo red the adsorption by the adsorbent for the process of cellulose from wood fiber gum, kaolinite and kaolinite activated impregnated cellulose. Furthermore, each standard solution concentration Congo red measured wavelength of maximum absorbance at $503 \mathrm{~nm}$ using Uv-Vis spectrophotometer. Having obtained the equation absorbance then made a straight line with the $\mathrm{x}$-axis dye concentration Congo red on the $\mathrm{y}$-axis as absorbance.

\section{Influence of Time Adsorption}

A $0.03 \mathrm{~g}$ of each adsorbent is added to $50 \mathrm{~mL}$ Congo red with a concentration of $40 \mathrm{mg} / \mathrm{L}$ in a separate flask. The adsorbent was stirred with a horizontal shaker at predetermined intervals. The variation of the adsorption time starts at $0,10,20,30,40,50,60$, $70,80,90,100,110$, and 120 minutes. Congo red that has gone through the adsorption process is separated and the absorbance was measured using a UV-Vis spectrophotometer. The amount of residual concentrations $(\mathrm{mg} / \mathrm{L})$, the amount of dye Congo red adsorbed $(\mathrm{mg} / \mathrm{L})$ was calculated using the equation of the calibration curve standard solution, while the rate of adsorption $\left(\mathrm{k}_{1}\right)$ can be calculated using the Langmuir equation as shown in formula 1.

\section{Influence of Temperature and Concentration of Congo red}

Effect thermodynamics Congo red dye adsorption by cellulose (control), kaolinite activated (control) and kaolinite impregnated cellulose is done through a series of experiments with varying concentrations of dye Congo red adsorption and temperature. A total of $0.03 \mathrm{~g}$ adsorbent cellulose (control) and kaolinite activated (control) were mixed with $50 \mathrm{~mL}$ of dye Congo red (5, 10, 15, 20, $25 \mathrm{mg} / \mathrm{L}$ ), and as much as $0.03 \mathrm{~g}$ kaolinite adsorbent impregnated cellulose mixed with $50 \mathrm{~mL}$ of dye Congo red (10, 20, 30, $40 \mathrm{mg}$ / L). The adsorbent which has been mixed with dye Congo red is stirred using a horizontal shaker for 30 minutes at varying temperatures $\left(30,40,50,60\right.$ and $\left.70{ }^{\circ} \mathrm{C}\right)$. The mixture is separated, then a solution of dye Congo red that has separated from the adsorbent measured absorbance values using a UV-Vis spectrophotometer to determine the concentration of residual dye Congo red after the adsorption process. The adsorption capacity (b), the adsorption energy (E) can be calculated using the Langmuir equation in formula 2 and 3 , while the adsorption enthalpy $(\Delta \mathrm{H})$, and the adsorption entropy $(\Delta \mathrm{S})$ can be calculated using formula 4 .

\section{Data Analysis}

The success of kaolinite with cellulose impregnation process was observed from FT-IR spectrum. Impregnation process optimal expected to form the adsorbent can be applied to the process of adsorption of the dye Congo red to see the parameters of kinetic and thermodynamic

Data kinetics of cellulose (control), kaolinite activated (control), and kaolinite impregnated cellulose is used to determine the rate of adsorption ( $\mathrm{k}_{1}$ assuming that the adsorption process that occurs following the model of the Langmuir adsorption equation as 


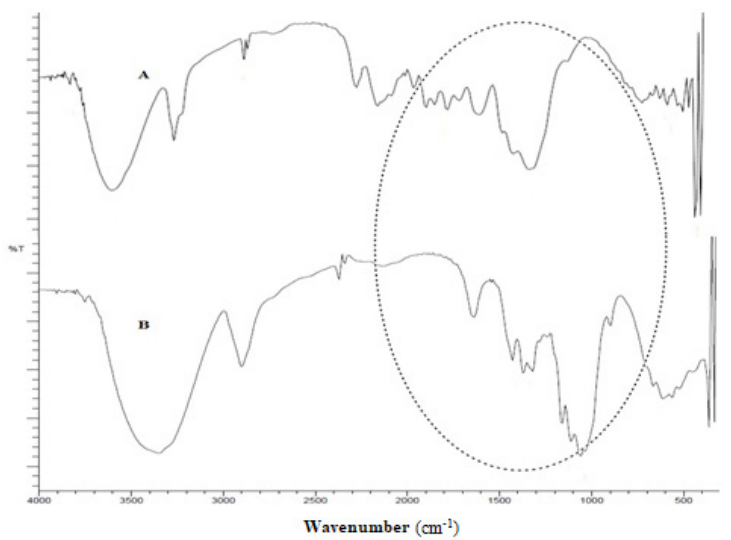

Figure 1. FT-IR spectrum of (A) the separation of cellulose wood fibers rubber (B) standard cellulose

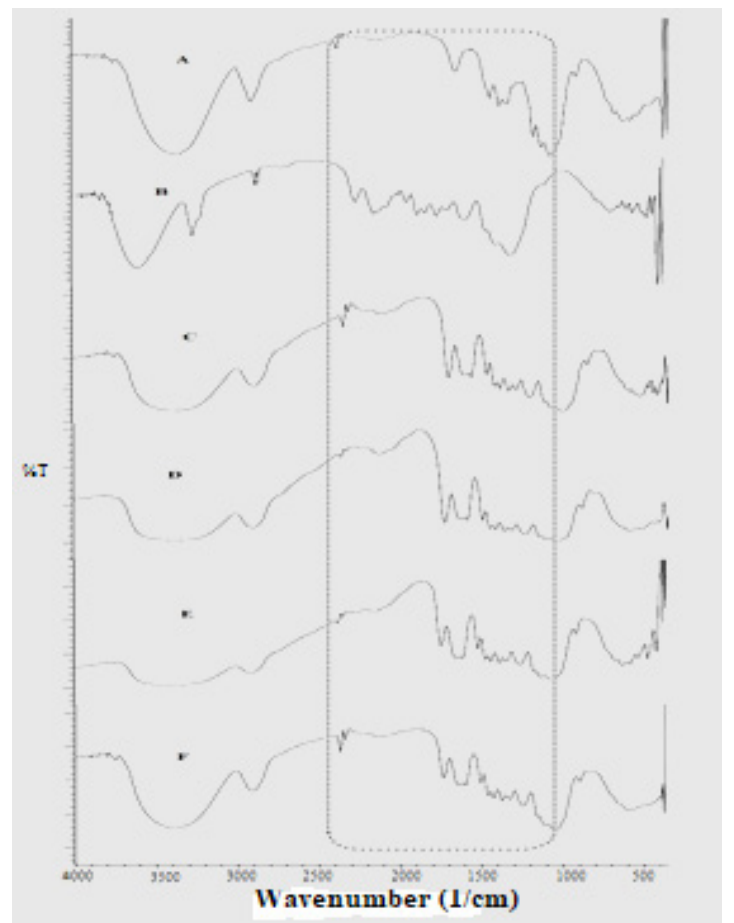

Figure 2. FT-IR spectrum of (A) standard cellulose; (B) the separation of the cellulose fibers rubber wood; cellulose washery $1 \mathrm{x}$

$$
\text { (C); 2x (D); 3x (E); 4x (F) }
$$

follows:

$$
\frac{\ln \left(C_{0} / C\right)}{C}=k_{1} \frac{t}{C}+K
$$

Where:

$\mathrm{C}_{0} \quad=$ initial concentration of Congo red $(\mathrm{mg} / \mathrm{L})$

$\mathrm{C}=$ concentration of residual Congo red $(\mathrm{mg} / \mathrm{L})$

$\mathrm{t} \quad=$ adsorption time $(\mathrm{min})$

$\mathrm{k}_{1} \quad=$ rate of adsorption $\left(\mathrm{min}^{-1}\right)$

$\mathrm{K}=$ constant adsorption equilibrium

Thermodynamic parameters of cellulose impregnated kaolinite adsorption processes such as adsorption capacity and adsorption energy can be determined using the Langmuir equation as follows:

$$
C / m=1 / b K+c / b
$$

$\mathrm{E}-\mathrm{RT} \ln \mathrm{K}$
Where:

$C=$ concentration of residual Congo red $(\mathrm{mg} / \mathrm{L})$

$\mathrm{m}=$ mol of Congo red adsorbed on kaolinite

$$
\begin{array}{ll}
\mathrm{K} & =\text { equilibrium constant } \\
\mathrm{b} & =\text { adsorption capacity }(\mathrm{mol} / \mathrm{g}) \\
\mathrm{E} & =\text { energy adsorption }(\mathrm{kJ} / \mathrm{mol}) \\
\mathrm{R} & =\text { constant } \\
\mathrm{T} & =\text { temperature }
\end{array}
$$

while to find the value of the distribution coefficient of adsorbate used the following equation:

$\ln K_{d}=-\frac{\Delta H}{R T}+\frac{\Delta S}{R}$

Description:

$\mathrm{K}_{\mathrm{d}}=$ distribution coefficient of adsorbate $(q e / \mathrm{Ce})$

$\Delta \mathrm{H}=$ enthalpy

$\Delta \mathrm{S}=$ entropy

$\mathrm{R}=$ constant

$\mathrm{T}=$ temperature

\section{RESULTS AND DISCUSSION}

\section{Identification and Characterization of Cellulose Results Sep- aration of Wood Fiber Rubber using Spectrophotometer FT- IR}

Fiber rubber wood taken from wood processing waste already separated, so that the residue obtained in the form of a mixture of cellulose, lignin and hemicellulose. Cellulose result of separation of rubber wood fibers identified using FT-IR spectrophotometer is then compared with the FT-IR spectrum of standard cellulose as presented in Figure 1.

In Figure 1 looks FT-IR spectra of standard cellulose showed absorption at wavenumbers $3348.42 \mathrm{~cm}^{-1}$ which is the stretching vibration of the hydroxyl group $(\mathrm{OH})$. Wavenumber in 2900.94 $\mathrm{cm}^{-1}$ indicates $-\mathrm{CH}$ vibration which is a constituent group of the cellulose structure and reinforced with vibration at wave number $1427.32 \mathrm{~cm}^{-1}$ and $1373.32 \mathrm{~cm}^{-1}$. CO group which is a carbon chain connecting the cellulose compound is located in the fingerprint region at wavenumber $1250-1030 \mathrm{~cm}^{-1}$ and a stretching vibration.

FT-IR spectra of the cellulose separation results show similarities with the standard cellulose, which in the area of $3410.15 \mathrm{~cm}^{-1}$ the hydroxyl $(\mathrm{OH}),-\mathrm{CH}$ group at wavenumber $2924.09 \mathrm{~cm}^{-1}$ and reinforced with vibration on wavenumber $1427.32 \mathrm{~cm}^{-1}, 1373.32$ $\mathrm{cm}^{-1}$ and $1327.03 \mathrm{~cm}^{-1}$ i.e. in the fingerprint region $1250-1050 \mathrm{~cm}^{-1}$ indicate the presence of ether groups (-CO). In the IR spectra of cellulose from wood fiber rubber looks still their unwanted vibration that is at wave number $1600-1700 \mathrm{~cm}^{-1}$ that indicates aromatic compounds making up the structure of lignocellulose. Therefore, necessary separation process can be continued in order in pure cellulose.

Cellulose separation of compounds undesirable done by soaking the back of cellulose using hydrochloric acid at a concentration of $0.1 \mathrm{M}$ for three hours while stirring followed by immersion using sodium hydroxide at a concentration of $0.1 \mathrm{M}$ with stirring for three hours. Soaking using $\mathrm{HCl}$ intended to break the hemicellulose and lignocellulose while $\mathrm{NaOH}$ solution is used to dissolve the lignin, hemicellulose and other compounds in order to get pure cellulose (Taflick et.al, 2017). Soaking using $\mathrm{HCl}$ and $\mathrm{NaOH}$ are repeated four times in order to obtain increasingly pure cellulose. 
Table 1. The moisture content and ash content of cellulose from wood fiber washing

\begin{tabular}{lll}
\hline Washing & $\begin{array}{l}\text { Water Content } \\
(\% \mathrm{w} / \mathrm{w})\end{array}$ & $\begin{array}{l}\text { Ash content } \\
(\% \mathrm{w} / \mathrm{w})\end{array}$ \\
\hline 1 & 6.52 & 6.86 \\
2 & 4.85 & 6.73 \\
3 & 3.96 & 6.00 \\
4 & 1.98 & 0.92 \\
\hline
\end{tabular}

Cellulose separation results are identified using a spectrophotometer FT-IR and spectra are then compared to standard cellulose.

Figure 2 show that the FT-IR spectrum of cellulose results $4 \mathrm{x}$ laundering has similarities with the standard cellulose IR spectra. Especially in the area of $2368.59 \mathrm{~cm}$ wave number ${ }^{-1}$ where the FTIR spectra of cellulose results showed absorption $4 \mathrm{x}$ laundering sharp and strong intensity in the region of the wave numbers compared to the FT-IR spectra of cellulose washery 1x, 2x and 3x. In the $1100-1600 \mathrm{~cm}^{-1}$, the absorption area for laundering proceeds $4 \mathrm{x}$ cellulose has similarities with FT-IR spectra showing the vibration standard cellulose - $\mathrm{CH}$ group.

Characterization of Wood Fibers Cellulose Rubber Results Washing through Content Determination of Water and Ash Content. Result of the determination content of moisture and ash content of cellulose from wood fiber rubber washing results are presented in Table 1.

Water content like presented in Table 1 shows the water can be removed by heating at a temperature of $100-110^{\circ} \mathrm{C}$. Determination of the water content of an adsorbent conducted to determine the hygroscopic properties of the adsorbent because of high water in the adsorbent will reduce his ability as adsorbent due to pores are filled molecules of $\mathrm{H}_{2} \mathrm{O}$ (Sharma et.al, 2017). In general, the desired moisture content has a low water content. It also deals with Waku save fuel to be used which in this case is cellulose from wood fiber rubber washing results. If the high water content in the storage cellulose cannot be done in the long term and its use will be limited. In this study, cellulose from wood fiber washing results $4 \mathrm{x}$ repetition has the smallest water content. In the first washing, the cellulose has a water content by $6.52 \%$ while the fourth laundering cellulose has a water content of $1.98 \%$. Furthermore, the determination of ash content in the cellulose from wood fiber rubber washing results.

The ash content indicates the rich content of metal oxides or mineral salts and impurities contained in the cellulose from wood fiber washing results. Based on the National Indonesian standard criteria for adsorbent ash content is a maximum of $2.5 \%$. Table 2 shows that the ash content of cellulose from wood fiber rubber decreases with decreasing water content. Based on the data in Table 2, it is known that cellulose from wood fiber washery four times has the lowest ash content is $0.92 \%$ in accordance with the terms of a maximum ash content of the adsorbent, to cellulose from the washing $1 \mathrm{x}, 2 \mathrm{x}$, and $3 \mathrm{x}$ exceeds the maximum ash content of an adsorbent.

Identification and Characterization of Natural Kaolinite and Activation using FT-IR spectrophotometer

Kaolinite has the characteristics of the bond, Si-O (wavenumber area around of 993, 1024, and $1112 \mathrm{~cm}^{-1}$ ), Si-O-Al (in the area around of $530 \mathrm{~cm}^{-1}$ ) and $\mathrm{OH}$ (in the wavenumber area around of 3684, 3668, 3651, and $3618 \mathrm{~cm}^{-1}$ ) (Spence and Kelleher, 2012). Vibration typical kaolinite which show ties to the kaolinite presented
Table 2. Data for kaolinite wave numbers

\begin{tabular}{ll} 
Wavenumbers $\left(\mathrm{cm}^{-1}\right)$ & Vibrations \\
\hline $3670-3656$ & Bend $(\mathrm{Al}-\mathrm{OH})$ \\
$3435-3433$ & Bend HOH \\
$1635-1629$ & HOH Stretch \\
$1100-1005$ & bend the Si-O \\
$916-915 ; 888-842$ & O-H deformation bound cations \\
$542-535$ & Bending Si-O-Al \\
$475-468$ & Stretch Si-O-Si \\
\hline
\end{tabular}

(Saikia et al, 2010)

in Table 2

In Figure 3a looks a typical absorption band at natural kaolinite in the area of wave number $3695.6 \mathrm{~cm}^{-1}$ and $3618.4 \mathrm{~cm}^{-1}$ that indicates $\mathrm{Al}-\mathrm{OH}$ stretch vibration which is characteristic of kaolinite. Uptake in the area of $3448.7 \mathrm{~cm}^{-1}$ and 1635.6 to $2368.5 \mathrm{~cm}^{-1}$ may indicate vibration $\mathrm{OH}$ observed almost in all silicate hydrate. Bond at $3448.7 \mathrm{~cm}^{-1}$ indicates the stretch vibration of $\mathrm{HOH}$ and 1635.6 $\mathrm{cm}^{-1}$ indicates $\mathrm{HOH}$ bending vibration. Strong absorption band appears at wavenumber $1026.1 \mathrm{~cm}^{-1}$ and $1002 \mathrm{~cm}^{-1}$ which show the stretch vibration of $\mathrm{Si}-\mathrm{O}$ as tetrahedral layers of kaolinite, while uptake in areas $918.1 \mathrm{~cm}^{-1}$ indicates $\mathrm{Al}-\mathrm{OH}$ bending vibration as octahedral layers of kaolinite. Vibration strain Si-O-Al appears at $547.7 \mathrm{~cm}^{-1}$, while the strong absorption bands appear on the area $470.6 \mathrm{~cm}^{-1}$ and $401.1 \mathrm{~cm}^{-1}$ that indicates the bending vibration of Si-O-Si (Saikia and Parthasarathy, 2010).

Natural kaolinite which has been characterized using FT-IR spectrophotometer is then performed the activation process. There are two stages in the activation process kaolinite namely heating at $400^{\circ} \mathrm{C}$ for two hours and acidification using sulfuric acid $\left(\mathrm{H}_{2} \mathrm{SO}_{4}\right)$ with various concentrations of $1 \%, 5 \%, 10 \%$ and $15 \%$. Activation by heating at a temperature of $400^{\circ} \mathrm{C}$ aims to remove impurities such as alkali metal or alkaline earth metal contained in the natural kaolinite (Gao et.al, 2016). Absorption bands seen in Figure 3b

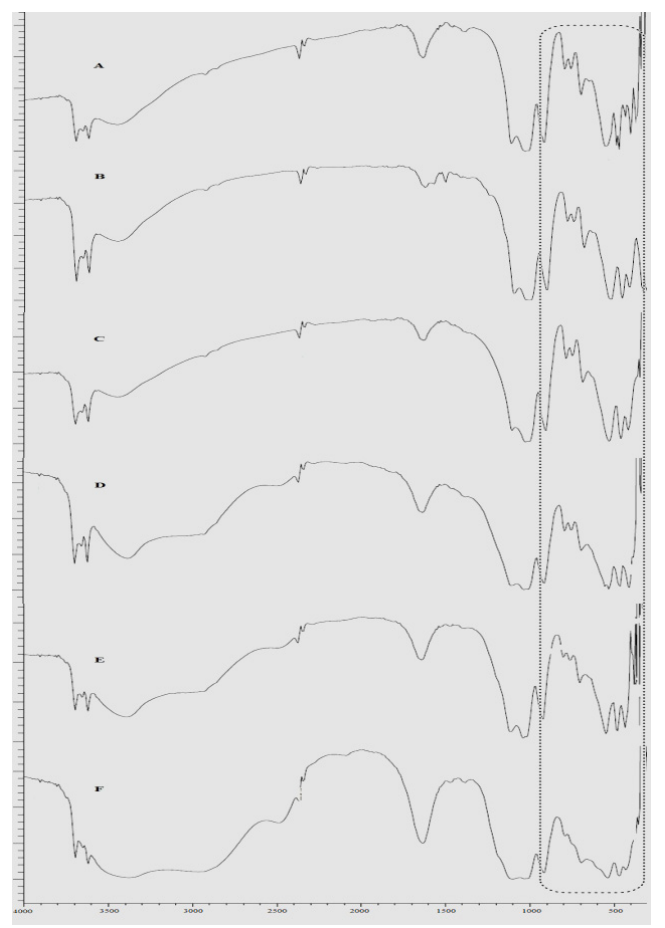

Figure 3. FT-IR spectrum of (A) a natural kaolinite; (B) kaolinite heating; and acidification result kaolinite $\mathrm{H}_{2} \mathrm{SO}_{4}$ (C) $1 \%$; (D) $5 \%$; (E) $10 \%$; and (F) $15 \%$ 


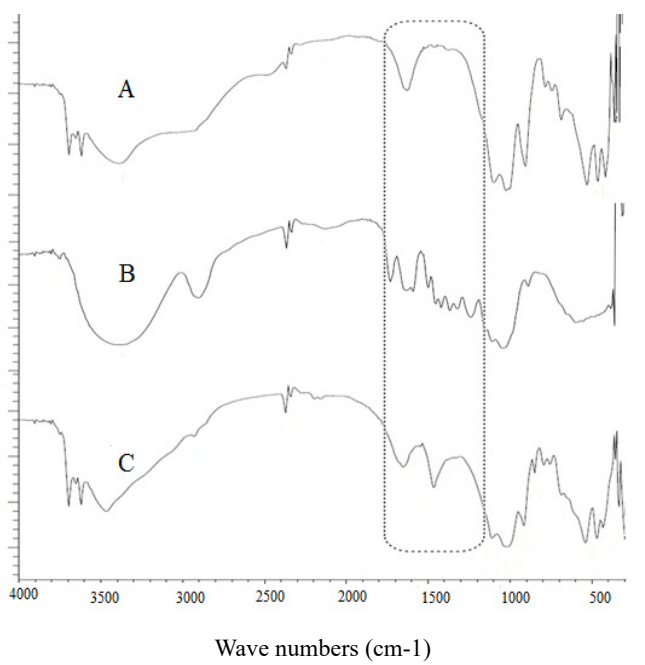

Figure 4. FT-IR spectrum of (a) kaolinite result of acidification of $\mathrm{H}_{2} \mathrm{SO}_{4} 10 \%$; (b) the cellulose of the wood fibers result laundering 4x; (c) kaolinite impregnated cellulose from wood fiber rubber

shows the shift in the bending vibration of $\mathrm{Si}-\mathrm{O}$ appearing at wave number $1018.4 \mathrm{~cm}^{-1}$ and stretch vibration of Si-O-Al appearing at $540.07 \mathrm{~cm}^{-1}$. Al-OH stretch vibrational still appears at wave number $3695.6 \mathrm{~cm}^{-1}$ and $3618.4 \mathrm{~cm}^{-1}$. Vibration bend and stretch $\mathrm{HOH}$ appear on the same wave numbers with natural kaolinite, which is $3448.7 \mathrm{~cm}^{-1}$ and $1635.6 \mathrm{~cm}^{-1}$. Vibration bending Si-O-Si remains on the wave number of $470.6 \mathrm{~cm}^{-1}$.

For activation using strong acids will produce kaolinite with active sites larger and larger surface acidity that will produce kaolinite with a higher adsorption capacity than before is activated (Wang et.al, 2016). From Figure 3 presented shows that the FT-IR spectrum of shifting, especially again in Figure $3 \mathrm{e}$ which result kaolinite acidification $\mathrm{H}_{2} \mathrm{SO}_{4} 10 \%$. Absorption bands seen in Figure $3 \mathrm{e}$ shows the shift of the $\mathrm{HOH}$ bending vibration that appears at wave number $3387 \mathrm{~cm}^{-1}$, Si-O stretch vibration that appears at wave number $1103.2 \mathrm{~cm}^{-1}$ and $1033.8 \mathrm{~cm}^{-1}$ and bending vibration $\mathrm{Al} \mathrm{OH}$ which appears at wave number $910.4 \mathrm{~cm}^{-1}$. Al-OH vibrational strain persists at $3695.6 \mathrm{~cm}^{-1}$. Vibration stretch $\mathrm{HOH}$ remains on the wave number $1635.6 \mathrm{~cm}^{-1}$.

Identification and Characterization of Kaolinite Result of impregnation with Wood Fibers Cellulose Rubber using FTIR spectrophotometer

Impregnation process kaolinite with rubber wood cellulose fiber made from mixing the two solutions. The solution I consisted of a mixture of $1.5 \mathrm{M} \mathrm{NaOH}$ and thiourea $1 \mathrm{M}$ and then added cellulose from wood fiber $4 \mathrm{x}$ rubber washing results. Solution II consists of kaolinite results of acidification $\mathrm{H}_{2} \mathrm{SO}_{4} 10 \%$ and $46 \%$ $\mathrm{NaOH}$ is added and ice cubes. The FTIR spectrum of kaolinite was presented in Figure 4.

From the Figure 4, it seen there are several groups making up the cellulose structure which - $\mathrm{CH}$ vibration that appears at wave number $2931.8 \mathrm{~cm}^{-1}$ and strengthened also by the emergence of vibration in wave numbers $1465.9 \mathrm{~cm}^{-1}$ and $1342.4 \mathrm{~cm}^{-1}$. This suggests that the cellulose compound capable of sticking and bonding with kaolinite. Absorption bands are seen in Figure 4c. From the Figure 4, it can see the shift of the $\mathrm{HOH}$ bending vibration that appears at wave number $3464.1 \mathrm{~cm}^{-1}$ with a strong intensity. $\mathrm{Al}-\mathrm{OH}$ vibrational stretch that is characteristic of kaolinite persists at $3695.6 \mathrm{~cm}^{-1}$. Si-O vibrational stretch as tetrahedral layers

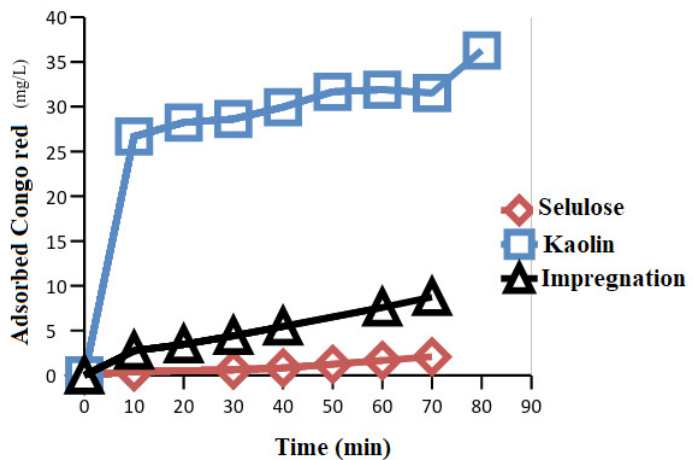

Figure 5. Effect of contact time Congo red $40 \mathrm{mg} / \mathrm{L}$ with adsorbent cellulose from wood fiber gum (control), kaolinite activated (control), and kaolinite impregnated cellulose to the amount of Congo red adsorbed

of kaolinite and $\mathrm{Al}-\mathrm{OH}$ bending vibration as octahedral layers of kaolinite persists at $1026.1 \mathrm{~cm}^{-1}, 1010.7 \mathrm{~cm}^{-1}$ and $918.1 \mathrm{~cm}^{-1}$. Vibration strain Si-O-Al remains on the wave number $540.07 \mathrm{~cm}^{-1}$ and bending vibrations of Si-O-Si also persists in the area of 470.6 $\mathrm{cm}^{-1}$ and $432.05 \mathrm{~cm}^{-1}$. Vibrations that appear in the FT-IR spectrum of Figure $4 \mathrm{c}$ has a lower intensity, due to the merger of two of the compounds causing the concentration contained in each of these compounds is reduced.

Impregnation process involves physical interaction between cellulose impregnated with kaolinite. This physical interaction occurred at the surface and are the result of physical force or involve intermolecular forces such as Van der Waals bonding. The success of the impregnation process can be seen in the FT-IR spectrum of Figure 4 wherein the cellulose constituent is - $\mathrm{CH}$ group appears at wave number $2931.8 \mathrm{~cm}^{-1}$ and reinforced with vibration at wave number $1465.9 \mathrm{~cm}^{-1}$ and $1342.4 \mathrm{~cm}^{-1}$ kaolinite and the new FT-IR spectrum is shown in Figure 4c.

Effect of Time Adsorption of Dye Congo Red using Adsorbents Kaolinite Activated (Control), Cellulose Results Laundering (Control), and Kaolinite impregnated cellulose and Determination of Kinetic Parameters

Effect of adsorption time to dye adsorption Congo red is done by encounters $0.03 \mathrm{~g}$ each adsorbent with dye solution is Congo red $50 \mathrm{~mL}$ with a concentration of $40 \mathrm{mg} / \mathrm{L}$. The adsorption process carried out with stirring during the adsorption contact time varied i.e. for 10 to 120 minutes. The observation of the effect of contact time dye adsorption Congo red with activated kaolinite, cellulose washery and kaolinite impregnated cellulose can be seen in Figure 5.

Figure 5 shows a concomitant increase in the adsorption amount of Congo red is absorbed relatively increased. At adsorbent cellulose from wood fibers visible rubber dye number Congo red increased continuously in time from 10 minutes to 70 minutes, but a decline in the next adsorption time increment. At the time of 70 minutes showed amount of Congo red the greatest adsorbed i.e. $2.08 \mathrm{mg} / \mathrm{L}$. On kaolinite adsorbent activated seen amount Congo red adsorbed increased in 10 minutes to the 80 minutes. At the time of 80 minutes showed amount of Congo red the greatest adsorbed i.e. $36.29 \mathrm{mg} / \mathrm{L}$. Whereas in kaolinite adsorbent impregnated cellulose also showed an increase in the time of 10 minutes until 40 minutes. At 60 minutes the amount of Congo red adsorbed decreased, but increased again to 70 minutes and further declined in the next time increment. At 70 minute, kaolinite impregnated cellu- 
Table 3. Parameter kinetic adsorption of Congo red to the adsorbent cellulose from wood fiber, activated kaolinite, and kaolinite impregnated cellulose

\begin{tabular}{ll}
\hline Adsorbent & $\mathrm{k}_{1}\left(\mathrm{~min}^{-1}\right)$ \\
\hline Activated Kaolinite & 0.026 \\
Impregnated Kaolinite & 0.002 \\
Cellulose & 0.001 \\
\hline
\end{tabular}

lose has the number of Congo red largest adsorbed i.e. $8.75 \mathrm{mg} / \mathrm{L}$.

Adsorption time data in Figure 5 can be used to determine the kinetic parameters of adsorption. Adsorption rate constant (k1) Congo red on each adsorbent using Langmuir-Hinshelwood equation. Data adsorption rate constant dye Congo red on each adsorbent is presented in Table 3 .

Table 3 shows that the activated kaolinite adsorbent having adsorption rate $\left(\mathrm{min}^{-1}\right)$ that is larger $0.026 \mathrm{~min}^{-1}$, kaolinite adsorbent impregnated cellulose has the adsorption rate of $0.002 \mathrm{~min}^{-1}$ while the adsorbent cellulose from wood fiber rubber have very little adsorption rate which is equal to $0.001 \mathrm{~min}^{-1}$. This is because adsorbate that in this study dye Congo red adsorbed on an adsorbent layer and the surface of the kaolinite activated causing the adsorption rate faster than kaolinite adsorbent impregnated cellulose and cellulose from wood fiber gum. Whereas in kaolinite adsorbent impregnated cellulose from wood fiber and rubber adsorption occurs in physics involving Van der Waals bonds, so that the adsorption rate is slower.

\section{Effect of Temperature and Concentration of Congo red and Determination of Thermodynamic Parameters}

The effect of Congo red dye adsorption temperature by cellulose adsorbents from rubber wood fibers, activated kaolinite, and cellulose impregnated kaolinite is presented in Figure 6, 7 and 8. In Figure 6,7 , and 8 it is seen generally that the greater the temperature $\left({ }^{\circ} \mathrm{C}\right)$ and the concentration $(\mathrm{mg} / \mathrm{L})$ the amount of Congo red adsorbed $(\mathrm{mg} / \mathrm{L})$ is also relatively increased, but some are decreasing at some temperature and concentration. The adsorption thermodynamic parameters include adsorption capacity (b), adsorption energy $(E)$, enthalpy $(\Delta H)$, and entropy $(\Delta S)$. The adsorption capacity data for each adsorbeWnt is presented in Table 4.

Table 4 shows that the activated kaolinite adsorbent has the largest adsorption capacity of $1000 \mathrm{mg} / \mathrm{g}$ at $70{ }^{\circ} \mathrm{C}$, whereas the cellulose impregnated kaolinite adsorbent and the cellulose adsorbent of rubber wood fibers at $40{ }^{\circ} \mathrm{C}$ and $50^{\circ} \mathrm{C}$ have the largest adsorption capacity of $500 \mathrm{~mol} / \mathrm{g}$ and $125 \mathrm{~mol} / \mathrm{g}$. In Table 4 also presents the adsorption energy data $(E)$ which shows on every adsorbent in general an increase in adsorption energy as temperature increases. In the cellulose adsorbent of rubber wood fibers (control) has the greatest energy at $50{ }^{\circ} \mathrm{C}$ of $4.96 \mathrm{~kJ} / \mathrm{mol}$, the activated kaolinite adsorbent (kaolinite) at $70{ }^{\circ} \mathrm{C}$ has the greatest energy of $10.22 \mathrm{~kJ} /$ mol, the impregnated kaolinite adsorbent at $40{ }^{\circ} \mathrm{C}$ has the greatest energy of $11.09 \mathrm{~kJ} / \mathrm{mol}$. The value of adsorption energy can be used to determine the type of adsorption that occurred i.e. physical adsorption or chemical adsorption (Isahak et.al, 2013). Thus the adsorption in this research can be classified as physical adsorption. Other thermodynamic parameters, such as enthalpy $(\Delta \mathrm{H})$ and entropy $(\Delta S)$ are presented in Table 5 .

The entropy value $(\Delta \mathrm{S})$ of Congo red adsorption by each of the adsorbents presented in Table 5 indicates a decrease in the degree of irregularity with increased Congo red $(\mathrm{mg} / \mathrm{L})$ concentration. This shows the regularity of the Congo red dyestuff absorbed on each adsorbent. In addition to the enthalpy value $(\Delta \mathrm{H})$ of Congo

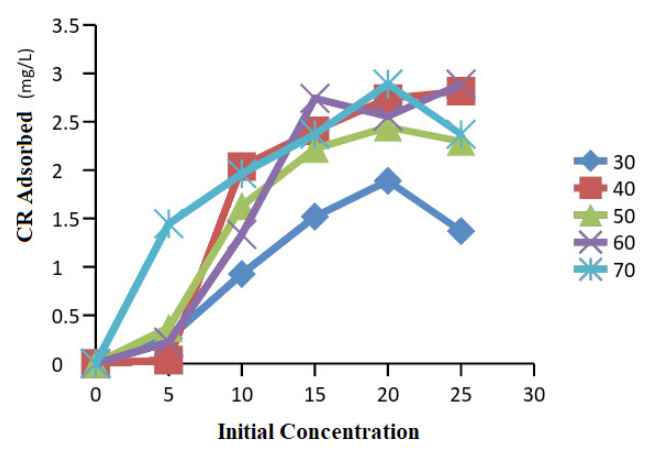

Figure 6. The effect of adsorption temperature and Congo red dye concentration on the amount of Congo red adsorbed by adsorbent of cellulose from rubber wood fiber

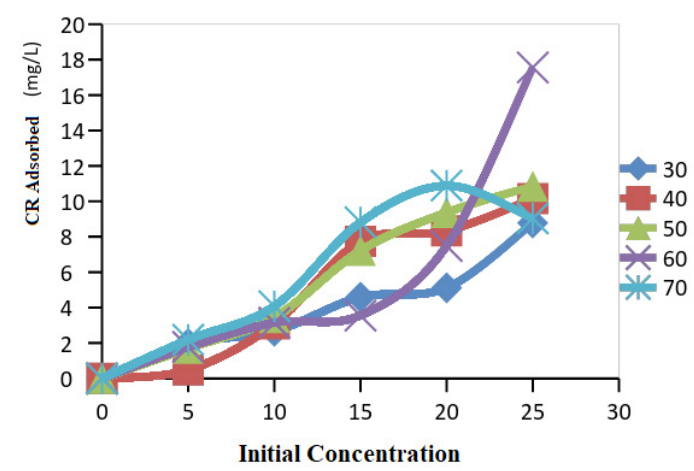

Figure 7. The effect of adsorption temperature and Congo red dye concentration on the amount of Congo red is adsorbed by activated kaolinite

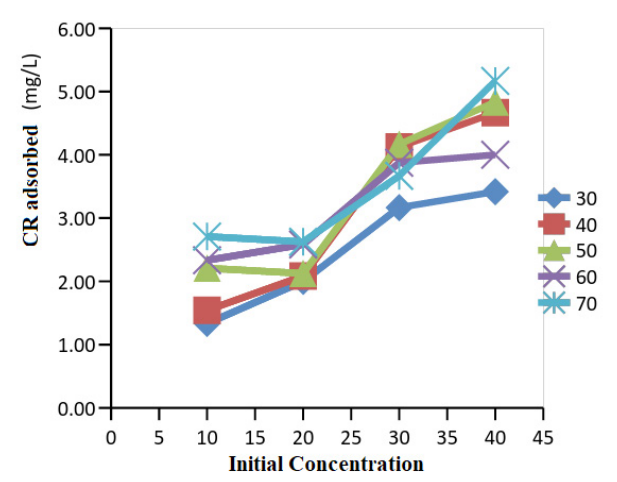

Figure 8. The effect of adsorption temperature and Congo red dye concentration on the amount of Congo red is adsorbed by impregnated cellulose kaolinite

red adsorption also decreases with increasing concentration.

\section{CONCLUSION}

The impregnation process involves the physical interaction between kaolinite and impregnated cellulose. This physical interaction occurred involving Van der Waals interaction. From the FT-IR spectrum data the kaolinite impregnation process with successful cellulose is characterized by wavenumbers $432.05 \mathrm{~cm}^{-1}, 918.12 \mathrm{~cm}^{-1}$, $1026.13 \mathrm{~cm}^{-1}$ and the appearance of peaks at wave numbers 2931.8 and $1465.9 \mathrm{~cm}^{-1}$ which shows the presence of the -CH group as the structural constituent of cellulose.

The adsorption process is studied through parameters of adsorption time, temperature, and Congo red concentration. The activated kaolinite adsorbent (control) adsorption process was optimum at 80 minutes, $70{ }^{\circ} \mathrm{C}$ and $5 \mathrm{mg} / \mathrm{L}$ with adsorption energy 
Table 4. Thermodynamic parameters (adsorption capacity and energy) of Congo red dye adsorption by cellulose adsorbents from rubber wood fibers (control), activated kaolinite (control) and impregnated kaolinite cellulose.

\begin{tabular}{lllll}
\hline Adsorbent & $\mathrm{T}\left({ }^{\circ} \mathrm{C}\right)$ & $\mathrm{R}^{2}$ & $\mathrm{~b}(\mathrm{~mol} / \mathrm{g})$ & $\mathrm{E}(\mathrm{kJ} / \mathrm{mol})$ \\
\hline & 30 & 0.988 & 333.33 & 6.19 \\
Kaolinite activated & 40 & 0.901 & 500 & 4.87 \\
(control) & 50 & 0.949 & 500 & 3.72 \\
& 60 & 0.958 & 200 & 5.31 \\
& 70 & 0.985 & 1000 & 10.22 \\
& 30 & 0.914 & 250 & 9.47 \\
Kaolinite impreg- & 50 & 0.906 & 500 & 11.09 \\
nated cellulose & 60 & 0.996 & 250 & 7.83 \\
& 70 & 0.997 & 166.67 & 5.87 \\
& 30 & 0.866 & 142.86 & 5.17 \\
& 40 & 0.904 & 37.04 & 0.35 \\
& 50 & 0.996 & 125 & 4.82 \\
Cellulose & 60 & 0.943 & 111.11 & 4.96 \\
& 70 & 0.940 & 100 & 2.35 \\
& & & & 3.32 \\
\hline
\end{tabular}

Table 5. Thermodynamic parameters (enthalpy and entropy) of Congo red dye adsorption by cellulose from rubber wood fibers, activated kaolinite, and impregnated cellulose kaolinite

\begin{tabular}{lllll}
\hline Adsorbent & $\mathrm{C}_{\mathrm{o}}$ & $\mathrm{R}^{2}$ & $\Delta \mathrm{H}(\mathrm{kJ} / \mathrm{mol})$ & $\Delta \mathrm{S}(\mathrm{kJ} / \mathrm{mol})$ \\
\hline & 5 & 0.933 & 112.45 & 0.32 \\
Cellulose (control) & 10 & 0.948 & 48.88 & 0.13 \\
& 15 & 0.996 & 18.92 & 0.05 \\
& 20 & 0.983 & 10.09 & 0.02 \\
& 25 & 1.000 & 22.70 & 0.06 \\
Kaolinite activated & 5 & 0.977 & 61.07 & 0.18 \\
& 10 & 0.998 & 12.94 & 0.038 \\
& 15 & 0.717 & 7.80 & 0.030 \\
Kaolinite impregnated cel- & 20 & 0.999 & 15.36 & 0.050 \\
lulose & 20 & 0.966 & 7.37 & 0.046 \\
& 25 & 0.970 & 14.23 & 0.054 \\
& 40 & 0.956 & 19.72 & 0.010 \\
& 20.728 & 8.89 & 0.029
\end{tabular}

of $10.22 \mathrm{~kJ} / \mathrm{mol}$. The impregnated cellulose kaolinite adsorbent undergoes optimum adsorption at 70 minutes, $40{ }^{\circ} \mathrm{C}$ and $10 \mathrm{mg} / \mathrm{L}$ concentration with adsorption energy of $11.09 \mathrm{~kJ} / \mathrm{mol}$. The cellulose adsorbent of rubber wood fibers undergoes optimum adsorption process at $90 \mathrm{~min}, 50^{\circ} \mathrm{C}$ and $5 \mathrm{mg} / \mathrm{L}$ with adsorption energy of $4.96 \mathrm{~kJ} / \mathrm{mol}$. In this study showed that adsorption occurs in the form of physical adsorption.

\section{ACKNOWLEDGEMENT}

The author would like to thank Integrated Research Laboratory Graduate School, Sriwijaya University for laboratory equipment and support of this research.

\section{REFERENCES}

Aung. L.L., Tertre. E., Petit. S. (2015). Effect of the Morphology (C) 2017 Published under the term of the CC BY NC SA 4.0 licence of Synthetic Kaolinites on Their Sorption Properties. Journal of Colloid and Interface Science, 433, 177-186.

Chemeda. Y.C., Deneele. D., Christidis. G.E., Ouvrard. G. (2015). Influence of Hydrate Lime on the Surface Properties and Interaction of Kaolinite Particles. Applied Clay Science, 107, 1-13.

Chong. M.N., Vimonses. V., Lei. S., Jin. B., Chow. C., Saint. C. (2009). Synthesis and Characterisation of Novel Titania Impregnated Kaolinite Nano-Photocatalyst. Microporous and Mesoporous Materials, 117, 1-1, 233-242.

Deng. L., Yuan. P., Liu. D., Annabi-Bergaya. F., Zhou, J., Chen. F., Liu. Z. (2017). Effects of Microstructure of Clay Minerals, Montmorillonite, Kaolinite, and Halloysite, on Their Benzene Adsorption Behaviours. Applied Clay Science, 143, 184-191.

Gao. W., Zhao. S., Wu. H., Deligeer. W., Asuha. S. (2016). Direct Acid Activation of Kaolinite and Its Effects on the Adsorption 
of Methylene Blue. Applied Clay Science, 126, 98-106.

Han. Y., Liu. W., Zhou. J., Chen. J. (2016). Interactions Between Kaolinite Al-OH Surface and Sodium Hexametaphosphate. Applied Surface Science, 387, 759-765.

Isahak. W.N.R.W., Ramli. Z.A.C., Ismail. M.W., Yusop. R.M., Hisham. M.W.M., Yarmo. M.A. (2013). Adsorption-Desorption of $\mathrm{CO}_{2}$ on Different Type of Copper Oxides Surfaces: Physical and Chemical Attractions Studies. Journal of CO2 Utilization, 2, 8-15.

Koteja. A., Matusik J. (2015). Di- and Triethanolamine Grafted Kaolinites of Different Structural Order as Adsorbents of Heavy Metals. Journal of Colloid and Interface Science, 455, 83-92.

Kovács. A., and Makó. E. (2016). Cooling as the Key Parameter in Formation of Kaolinite-Ammonium Acetate and Halloysite Ammonium Acetate Complexes Using Homogenization Method. Colloids and Surface A: Physicochemical and Engineering Aspects, 508, 70-78.

Pietzsch. A., Nisar. J., Jämstrop. E., Gråsjo. J., Århammar. C., Ahuja. R., Rubensson. J-E. (2015). Kaolinite: Defect Defined Material Properties-A Soft X-ray and First Principles Study of the Band Gap. Journal of Electron Spectroscopy and Related Phenomena, 202, 11-15.

Said. M and Palapa. N.R. (2017). Adsorption of Congo red Using $\mathrm{Mg} / \mathrm{Al}$ Hydrotalcite. Science and Technology Indonesia, 2, 17 21.

Saikia, BJ, and Parthasarathy, G. (2010). Fourier Transform Infrared Spectroscopic Characterization of Kaolinite from Assam and Meghalaya, Northeastern India. J. Mod. Phys. 1: 206-210.
Sasmal. D., Maity. J., Kolya. H., Tripathy. T. (2017). Study of Congo Red Dye Removal From Its Aqueous Solution Using Sulfated Acrylamide and N,N-dimethyl Acrylamide Grafted Amylopectin. Journal of Water Process Engineering, 18, 7-19.

Sharma. S., Lin. C-L., Miller. J.D. (2017). Multi-Scale Features Including Water Cntent of Polymer Induced Kaolinite Floc Structures. Mineral Engineering, 101, 20-29.

Spence. A., Kelleher. B.P. (2012). FT-IR Spectroscopic Analysis of Kaolinite-Microbial Interactions. Vibrational Spectroscopy, 61, 151-155.

Taflick. T., Schwendler. L.A., Rosa. S.M.L., Bica. C.I.D., Nachtigall. S.M.B. (2017). Cellulose nanocrystals From Acacia-Bark-Influence of Solvent Extraction. International Journal of Biological Macromolecules, 101, 553-561.

Unuabonah. E.I., Olu-Owolabi. B.I., Adebowale. K.O., Ofomaja. A.E. (2007). Adsorption of Lead and Cadmium Ions From Aqueous Solutions by Tripolyphosphate Impregnated Kaolinite Clay. Colloids and Surfaces A: Physicochemical and Engineering Aspects, 292, 202-211.

Wang. X., Huang. Y., Zhong. Z., Pan. Z., Liu. C. (2016). Theoretical Investigation of Cadmium Vapor Adsorption on Kaolinite Surfaces With DFT Calculations. Fuel, 166, 333-339.

Yu. C.Y., Chow. J.K., Wang. Y-H. (2016). Pore-Size Changes and Responses of Kaolinite with Different Structures Subject to Consolidation and Shearing. Engineering Geology, 202, 122131. 